\title{
Ciência, tecnologia e sociedade: ensino de Ciências no referencial pós-estruturalista
}

Samuel Molina Schnorr ${ }^{1}$ Carla Gonçalves Rodrigues ${ }^{2}$

\section{Resumo}

$\mathrm{Na}$ presente investigação, objetivou-se analisar, a partir do referencial teórico e metodológico pós-estruturalista, os conceitos de Ciência, Tecnologia e Sociedade na trama com a Educação e com o Ensino de Ciências. Como substrato teórico são utilizadas obras de Michel Foucault, Gilles Deleuze e Felix Guattari, ofertando pistas para ampliar a discussão destes conceitos. Na reunião dos saberes investigados, afirma-se um pensamento científico que desenvolve a produção de sentidos para a Educação. Diante do exposto, pensa-se em um ensino que crie estratégias de existências, que reivindique a trama de teorias e práticas, operando os conteúdos científicos na sociedade.

Palavras-chave: Ensino de Ciências; Pós-estruturalismo; Sociedade.

\begin{abstract}
The main goal of the present research was to analyse, from the poststructuralist theoretical and methodological framework, the concepts of Science, Technology and Society under the perspective of education and science education. Michel Foucault, Gilles Deleuze and Felix Guattari works are used as a theoretical substrate to expand the discussion about these concepts. As a result, a scientific thought that develops the production of meanings for education is found. In view of the above, it is proposed a teaching which creates strategies of existences and incorporates the net of theories and practices, operating the scientific contents on the society.
\end{abstract}

Keywords: science education; Post-structuralism; Society.

\footnotetext{
${ }^{1}$ Doutorando em Educação pela Universidade de São Paulo.

2 Professora associada 2 na Universidade Federal de Pelotas, atua no PPGE linha 1: Filosofia e História da Educação.
} 


\section{Introdução}

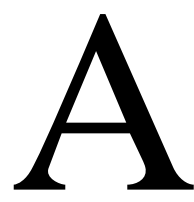

sociedade tem sofrido diversas mudanças ao longo do tempo, no que concerne à sua própria construção e ao que se pensa e é produzido pelo homem. Nas descobertas científicas e suas aplicações tecnológicas, relacionam-se os desenvolvimentos nas leis jurídicas, na política, no modo de viver coletivo, na cultura, na ética e no meio ambiente. O modo de vida contemporâneo recebe influências da associação entre ciência e tecnologia, logo, essas áreas são estudadas cada vez mais tentando entender os resultados desse momento atual. A Educação e o Ensino de Ciências são campos que comtemplam essas temáticas e direcionam os modos como se entende os processos científicos e tecnológicos.

Observa-se, ao longo da história pedagógica, uma tendência de trazer fatos do cotidiano para a sala de aula, utilizando o contexto em que vive o aluno para o desenvolvimento dos conteúdos escolares, valorizando seus saberes prévios ao mediar algum processo científico (CHASSOT, 2008). Atualmente, o Ensino de Ciências tem o objetivo de disseminar uma cultura científica que eduque as formas de pensar dos estudantes e que possa ser aplicada na sociedade, relacionando o seu espaço de vivência (FAGUNDES, 2009).

Um dos pressupostos básicos da Ciência é que, sendo o mundo entendido pelo uso da razão e por meio do método científico, pode-se produzir novos conhecimentos, bem como corrigir e integrar os que já existem. Desenrola-se, assim, um período de exploração contínua dos recursos naturais e de mudanças climáticas na justificativa de que, em nenhum outro tempo da história da civilização humana, existia uma expectativa de vida tão alta e tantas oportunidades. Discutir esse avanço é, no mínimo, ir contra a importância desse progresso na sociedade, mesmo que grande parte da população não o usufrua ou integre esse movimento, oportunizando questionar qual é a real importância dessas melhorias. Segundo Auler e Delizoicov (2006), nesta concepção, há menos espaços para indagações, pois está alicerçada em três pilares: o determinismo 
tecnológico; a neutralidade das decisões tecnocráticas; e a perspectiva salvacionista da Ciência e da Tecnologia.

A literatura científica passa a desenvolver não só a aquisição de conhecimentos, mas também a ampliação de competências e raciocínios de outras áreas do saber que possam oferecer um distinto sentido a ideias e acontecimentos do cotidiano. O estudante, dessa forma, seria capaz de traduzir, interpretar os feitos, as deficiências dos empreendimentos científicos, tecnológicos em termos das funções humanas e sociais que os acompanham dia a dia. Sendo assim, é fundamental que os sujeitos da Educação desenvolvam o Ensino de Ciências como meio para a promoção da compreensão do contexto social que os envolve, tornando-se importante investigar a Ciência, Tecnologia e a Sociedade para que nestas possam agir e operar transformações.

Na prática de sala de aula em diversas disciplinas, tais como Física e Biologia, essas competências não são compatíveis a uma Ciência apresentada de forma tradicional, compartimentada e distante da realidade dos educandos, já que dificulta os processos de ensino e aprendizagem, distanciando teoria e prática, conforme argumentam Chassot (2008), bem como Auler e Delizoicov (2006). Nesse sentido, é fundamental que se apresente outros modos de pensar a Educação e o Ensino de Ciências, fomentando questionamentos sobre conceitos tidos como solidificados às perspectivas de ensino e ganham uma aceitação social.

Por outro lado, os conceitos de Ciência, Tecnologia e Sociedade são estudados sistematicamente por diversos autores que constroem teorias distintas, para explicar os fenômenos respectivos a estes, suas relações e são utilizados de diversos modos na Educação. Ainda, variam as divisões de tempos históricos, bem como o foco das diferentes análises. Aqui, pretendese desenvolver um estudo a partir dos conhecimentos construídos por Michel Foucault, Gilles Deleuze e Félix Guattari, permitindo realizar análises que contribuam com o conhecimento na Educação e no Ensino de Ciências. 
Importa, neste momento, discutir essas análises foucaultianas e deleuzianas por entender que se adequam, cronologicamente, ao surgimento e estabelecimento das perspectivas teóricas e práticas que inundam o Ensino de Ciências e a escola. Além disso, discutem-se teorias educacionais e a instituição escolar, com seus conceitos, práticas e princípios advindos dessas constituições sociais e que, ainda hoje, repercutem na Educação. Assim, serão abordados os estudos realizados pelos autores referidos no viés pós-estruturalista para problematizar os conceitos de Ciência, Tecnologia e Sociedade, que permitirão aventar outras possiblidades para pensar o Ensino de Ciências.

Portanto, o objetivo principal desta investigação é analisar, a partir do referencial teórico pós-estruturalista, o conceito de Ciência, Tecnologia e Sociedade, desenvolvendo-o desde os estudos de Foucault, Deleuze e Guattari na trama com a Educação e o Ensino de Ciências. Ainda, problematizar e elaborar pistas do que ainda pode ser questionado nos estudos desta temática, para colaborar com o conhecimento científico sobre o tema, com o intuito de ventilar outras perspectivas às verdades já instituídas no Ensino de Ciências. Ao longo deste texto, serão tecidos exemplos e questionamentos aos conceitos desenvolvidos, possibilitando, desse modo, trazer concretude e aproximações as atuais concepções de Educação, mais especificamente do Ensino de Ciências.

\section{Procedimentos da pesquisa}

$\mathrm{Na}$ vertente pós-estruturalista, substrato teórico e metodológico desta pesquisa, é suscitada uma pluralidade de saberes, que produzem questionamentos e provocações em áreas tidas como esgotadas. Esse caminho aqui adotado analisa as relações educacionais contemporâneas, em especial, no foco dos estudos do Ensino de Ciências, reconhecendo a multiplicidade que abrange essa área e as diversas leituras que cabem nesse território.

No sentido de potencializar a pesquisa na área do Ensino de Ciências, é possível promover um diálogo com o pós-estruturalismo, principalmente 
com o trabalho de Foucault, Deleuze e Guattari, e ofertar outras possibilidades de se pensar os conceitos de Ciência, Tecnologia e Sociedade.

Para isso, analisa-se especificamente textos que esses autores discorrem nomeadamente sobre os conceitos de Ciência, Tecnologia e Sociedade: no volume 5 do livro Mil Platôs: capitalismo e esquizofrenia, no platô $\hat{~}^{3}$ 12, denominado: 1227 - Tratado de nomadologia: a máquina de guerra (DELEUZE; GUATTARI, 2012), aparecem as concepções de Ciência régia e nômade, ou ainda chamadas de maior e menor. Portanto, neste texto, aborda-se os conhecimentos científicos em relação ao Ensino de Ciências.

A via da tecnologia na qual se transita é a partir da análise do texto Tecnologías del yo de Michel Foucault (2008) que trata do discurso, da biopolítica e do "eu", que aqui serão relacionados ao campo educacional. Outrossim, pensa-se os conceitos de sociedade disciplinar, principalmente no livro Vigiar e Punir (FOUCAULT, 1987), e de controle, no texto Postscriptum sobre as sociedades de controle (DELEUZE, 1992).

Portanto, reuniu-se textos que tratam dos conceitos de Ciência, Tecnologia e Sociedade que serão analisados nesta pesquisa e as apropriações serão realizadas para produzir algo ou fomentar uma força capaz de abalar o já estruturado, tecendo questionamentos para o Ensino de Ciências. Exemplos advindos do campo empírico são trazidos à tona, na possibilidade de dar concretude e consistência ao movimento teórico realizado, costurando teoria à prática. No texto, realiza-se a análise da Ciência, Tecnologia e Sociedade pelo viés do pós-estruturalismo e nas considerações finais agenciamos a reunião desses três conceitos na perspectiva do Ensino de Ciências.

\footnotetext{
${ }^{3} \mathrm{O}$ livro é organizado em quinze "platôs", entendidos como uma multiplicidade conceitual, que podem ser lidos de forma independente. Na versão brasileira, da Editora 34, foram divididos em cinco volumes.
} 


\section{A Ciência em uma perspectiva pós-estruturalista}

A teoria pós-estruturalista implica evidenciar a posição do pesquisador, compromissos, contextos e contingências, estando no próprio questionamento a Ciência enquanto lugar da verdade. No combate às ideologias científicas, tal como a sociedade põe a funcionar, a teoria pósestruturalista investiga os envolvimentos do uso de conceitos dúbios de Ciência e das verdades, usando-os como defesa e conservação de suas posições. Do mesmo modo, o uso dos resultados de testes de coeficiente de inteligência, para seleção em universidades e escolas no sistema educacional, pode ser interpretado de forma imprecisa. Esses conjuntos de conhecimentos são defendidos, afirmando-se por meio do método científico e devem, sendo assim, ser essenciais para avaliações de alunos, tomados como decisivos para classificação dos estudantes.

Nesse contexto, Deleuze e Guattari pensam a Ciência régia ou maior com o seu poder a partir de teoremas inquestionáveis, buscando transformar os movimentos heterogêneos e subvertê-los em conceitos e categorias. A ciência maior reúne os conhecimentos considerados hegemônicos que possuem o reconhecimento dos cientistas e são incorporados em disciplinas, como a biologia e a física. Possuem, ainda, uma aceitação social e fazem parte da prática científica, sendo o substrato para que a ciência tenha uma base sólida e tente se manter imune a descobertas que não são por ela mesma pensadas, verificadas e testadas. O Ensino de Ciências ganha destaque na ciência maior como uma operação segura e viável para a produção de conhecimento e que, ao mesmo tempo, ensina o método científico aos estudantes, afirmando uma formação científica por essa via considerada principal.

O conceito de Ciência maior parte das hipóteses advindas do método científico, que trata o objeto de estudo isoladamente e fragmentado, tentando compreender e fazer a pesquisa na ordem do significado. Possui anseios de organização e classificação, dividindo amostras em mais ou menos importantes, simples ou complexas, erguendo, assim, teorias totalizantes e axiomáticas. Sustentadas nesse meio de cultivo, optam por 
definir e concretizar, formam um modelo único. Por conseguinte, sufocam outros contornos do conhecimento, os quais não se baseiam em suas epistemologias e metodologias. Para sustentar a característica de via única, a Ciência maior institui ordens e procedimentos, que garante a continuação de tal caminho. Aquilo que foge, que escapa dessas estruturas estabelecidas é inferiorizado.

A tendência do conhecimento científico é ser conduzido a partir de uma via única, de algo já instituído, ancorado em regras moldadas e organizações, com formas imutáveis que sustentam o método e as explicações. Tal qual a rotulação de científico é dada às práticas e pesquisas publicadas, em um formato específico, em revistas destinadas para este fim, que carregam um status de legitimadora e sancionadora de o que é considerado ou não Ciência.

Como exemplo, apresenta-se a pesquisa de Andrade e Carvalho (2002), que relaciona a produção de etanol à preservação ambiental, ocorrendo a partir de uma tecnologia nacional, que, por usar a cana de açúcar para produção de um combustível renovável, é certificado como sustentável, preservando a natureza ${ }^{4}$. Entretanto, nesse exercício escolar relatado por Andrade e Carvalho (2002), não há ressalvas quanto a essa fabricação, que produz diversas problemáticas, tais como o desmatamento gerado pela monocultura da cana, a condição social e trabalhista da mão de obra empregada, o primitivo processo de colheita que obriga a queima da matéria-prima, liberando, também, gases poluentes na atmosfera. Em uma relação com a Ciência maior, o fato de essa experiência utilizar um método, aparatos tecnológicos, estar sendo empregada na escola e publicada em uma revista garantem um caráter científico, onde verdades e conceitos legitimadores são postos a funcionar e são inquestionáveis.

Por outro lado, a Ciência nômade ou menor se desenvolve nos interstícios desse cenário, não possuindo como finalidade a busca de um

\footnotetext{
${ }^{4}$ Essa preferência é pelo fato de o etanol não produzir dióxido de enxofre quando é queimado, ao contrário da gasolina, que polui a atmosfera, contribui para o aumento do buraco da camada de ozônio e aumento da temperatura global, problemáticas e discursos ambientais recorrentes atualmente.
} 
desenvolvimento autônomo e de esclarecimentos. A Ciência menor agregaria os saberes que ainda não possuem um status científico propriamente dito, pois não se consolidam como um conhecimento que pode ser encontrado em uma disciplina. Esses saberes não são encontrados através do método científico e tampouco são considerados hegemônicos, pois não possuem um ordenamento social e científico.

Esses saberes menores são particulares, restritos em uma necessidade local e não se utilizam do aparato técnico e científico para serem empregados. De acordo com Deleuze e Guattari (2012), Ciência maior e Ciência menor coexistem, entretanto, a maior sempre tenta convocar esses saberes menores para uma institucionalização própria de um conhecimento maior, há sempre uma relação de captura e criação que fazem com que essas ciências se agenciem em um jogo de poderes.

A Ciência menor tangencia a maior, sem pretensões de obter um estado único de verdade, tentando escapar dos métodos e organizações. Não possui posição duradoura e as incongruências transitam dentre as criações possíveis de serem feitas sem representar um erro ou falha no processo. É na ênfase da experimentação que passa a construção de um movimento nômade, a criatividade, que, no decorrer das vivências dos alunos na instituição escolar, acabam sendo reprimidas, e considerada singular para a formação de um sujeito de uma Ciência menor. Ainda, apontam-se discrepâncias entre os pesquisadores científicos: um ligado a instituições hegemônicas que visam a padrões, formas e verdades, enquanto o outro tem estima pelo singular, criações e inquietações.

Nesse sentido, o problema adquire um viés questionador, inquieto, portador de singularidades, que ultrapassa obstáculos. Rejeitando a busca de constantes e leis, a partir de variáveis, o procedimento é pôr as variáveis em mutação contínua, captando singularidades da matéria, dos micromovimentos, uma Ciência à margem das técnicas e do sentido legalizado estabelecido pela História. Menos interessa a sua legitimação por meio do método científico, mas, sim, como a reunião de saberes opera 
determinados conceitos resultando em uma prática efetivamente ligada à sociedade, na tentativa de beneficiá-la.

Como exemplo de aplicação de uma Ciência menor, cita-se a prática pedagógica, realizada no Ensino Fundamental, por meio de temas sociocientíficos, pelos pesquisadores Mundim e Santos (2012). Apontam uma abordagem no Ensino de Ciências com as seguintes tramas: plantas, água, recursos naturais, metais, atividades físicas, problemas globais e cinema. A experiência foi trabalhada em uma turma do oitavo ano do ensino fundamental de uma escola pública. O tema estudado foi alimentação e vida saudável. Os resultados da pesquisa realizada indicam que essa abordagem propicia aos alunos relacionarem conhecimento científico com situações de sua vivência. Sem a preocupação de conceitos e métodos, os autores utilizaram os saberes dos estudantes agregados às aplicações sociais para promover os processos de ensino e aprendizagem. Os exercícios tangenciaram os livros, os conteúdos e as regras previamente definidas e investiram em uma Ciência aqui dita menor, tramada à contemporaneidade.

A Ciência régia é pensada por teoremas axiomáticos, tratando-os como inquestionáveis, inabaláveis, passíveis de produzir verdades carregadas de interesses, que colidem com a corrente problemática. A Ciência do Estado refuta todas as invenções da nômade, subjugando-a ao seu imperialismo e determinismo, aproveita o que pode e usa aquilo que interessa. Minimiza os achados da nômade transformando-os em produções sem o rigor científico, anula e reprime as criações. De acordo com Deleuze e Guattari (2012), o mais importante são os fenômenos fronteiriços: zonas que tangenciam as duas Ciências, onde uma exerce influência sobre a outra, a nômade desempenha uma força sobre a do Estado e esta apodera-se e decompõe os dados da anterior.

A exploração e a pulverização de conteúdos na Educação, bem como no Ensino de Ciências, por meio de conhecimentos que tenham em sua base questões relacionadas à Ciência, possuem no controle, na homogeneização, as principais realizações do poder. As considerações sobre essa perspectiva educacional estão fortemente embasadas em questões de caráter político e 
econômico. A Ciência é utilizada como a vontade da verdade (FOUCAULT, 2012), que elabora saberes e efeitos. Logo, o seu acontecimento, principalmente nos laboratórios, centros de pesquisas, tem sua produção alçada a uma grande verdade, reproduzida em livros, também didáticos, artigos acadêmicos, consolidando um discurso com pretensões científicas.

Nestes espaços, principalmente, encontram-se discursos que são associados a uma cultura de Ciência maior, pois, a partir de um parâmetro nacional, há tentativas de homogeneização do ensino, como se a aprendizagem pudesse se dar igual para todos, ingredientes que se afastam de um pensamento nômade e singular. Nessa esteira, questionam-se, também, os livros didáticos que possuem uma única edição para todo o Brasil, provocando uma linearidade em relação aos exemplos que podem ser abordados dentro da Biologia, como animais e plantas de uma determinada região, menos contemplados devido à diversidade encontrada no país. As mesmas estruturas, produzida por autores tradicionais nessa área, são perpetuadas a cada impressão, fomentadas por aparelhos de Estado, caso do Ministério da Educação, por meio de $\operatorname{programas}^{5}$ que, por mais perto que possam se aproximar de uma realidade heterogênea brasileira, reproduzem, ainda, práticas, experiências, conceitos hegemônicos, que pouco oferecem espaço para problematizações e contextualização.

Enfim, existe uma defesa do Ensino de Ciências nos espaços educacionais com a Ciência maior. Contudo, pode-se tentar passar a encaminhar os saberes desenvolvidos dentro desse campo do conhecimento em uma outra via, que leve em consideração as multiplicidades criadas a partir da experiência e não uma verdade única. Em suma, a Ciência nômade se oferece como possibilidade de soma na força de pensar, não somente pelos conceitos estudados, mas também por realçar o pensamento enquanto criação, agregado ao mundo, no afastamento de ideologias e preconceitos,

\footnotetext{
${ }^{5}$ Cita-se como exemplo o Programa Nacional do Livro Didático (PNLD), que tem como principal objetivo subsidiar o trabalho pedagógico dos professores por meio da distribuição de coleções de livros didáticos aos alunos da Educação Básica. Após a avaliação das obras, o Ministério da Educação (MEC) publica o Guia de Livros Didáticos com resenhas das coleções consideradas aprovadas. $\mathrm{O}$ guia é encaminhado às escolas, que escolhem, entre os títulos disponíveis, aqueles que melhor atendem ao seu projeto políticopedagógico. Fonte: http://portal.mec.gov.br/index.php. Acesso em junho de 2017.
} 
priorizando essas possibilidades nessa contemporaneidade. Assim, os exercícios dessa Ciência são atravessados por práticas inerentes ao social, assegurando-se enquanto procedimentos que procedem do vivido, que não buscam respostas e verdades, mas questionamentos que favoreçam uma relação mais próxima do conhecimento com os estudantes.

\section{Tecnologia do eu na Educação e no Ensino de Ciências}

O estudo realizado por Angotti e Auth (2001) demonstra como a crescente evolução e utilização de novas tecnologias vem acarretando profundas mudanças no meio ambiente, nas relações e nos modos de vida da população, colocando os indivíduos diante de novos desafios, cuja maioria dos sujeitos da educação, de acordo com os autores, não estão preparados para enfrentar. Como possibilidade para melhor discernir situações desse tipo e atuar sobre elas, propõem atividades didático-pedagógicas direcionadas para uma alfabetização científica e tecnológica. Tem como base aspectos históricos e epistemológicos, atentando para a questão das concepções, valores e atitudes dos indivíduos nas suas ações em sociedade, perspectiva enfatizada na educação.

No Ensino de Ciências o emprego das tecnologias vem sendo explorado, sobretudo, a partir de outras formas de desenvolver o conhecimento, mas, também, novos recursos e processos de aprendizagem diferente dos tradicionais. A interação com o aluno, o seu aproveitamento nos conteúdos, a capacitação de professores, para trabalhar com as ferramentas disponíveis, implica diversas formas de pensar, podendo ser discutidas, inclusive, as bases teóricas da formação docente e sua compatibilidade com as representações sociais. Nesse caso, a educação está imbricada em ver os fenômenos tecnológicos na escola aliando metodologias na busca de uma maior interatividade, além de disponibilizar tais recursos.

A tecnologia já possui um território assegurado nas discussões das práticas de ensino e experiências escolares, seja pela literatura, pela pesquisa, ou até mesmo pelos cursos de formação docente. Conforme as 
investigações realizadas nesta pesquisa, a exaltação das metodologias tecnológicas e dos saberes críticos da educação constituem-se em axiomas, dos quais, poucas dúvidas são levantadas (ANGOTTI; AUTH, 2001). Esse entendimento transita entre os estudos e aplicações do Ensino de Ciências e da educação. Porém, aqui, as indagações relativas a essa temática vão além das consequências listadas pelo senso comum: as distrações que a internet pode causar, o distanciamento do convívio pessoal, a falta de infraestrutura e o despreparo dos professores na sua utilização.

Atualmente, discursos carregados de poder produzem verdades, atravessam, constituem os sujeitos deste tempo, com chamadas persuasivas e sedutoras, inseridos nessa sociedade, de constantes desenvolvimentos tecnológicos e científicos. Provocar essas questões deslocando o entendimento de tecnologia, é o que aqui se tenta fazer, com a inquietação da visão tecnicista e pouca aprofundada nas discussões das subjetividades dos sujeitos envolvidos nesses processos. Nesta pesquisa, atenta-se para as tecnologias do eu, definidas por Foucault (2008), como as práticas que favorecem um modo de relação do sujeito consigo mesmo, que recusa a pressuposta de uma totalidade subjetiva, um fundamento a ser seguido.

Trata-se de colocar a si próprio como cerne da reflexão ${ }^{6}$, mas alocarse descolado dos atributos impostos pelo saber moderno, do poder disciplinar e normalizador, de uma determinada forma moral orientada para uma unificação do eu. Desse modo, evitaria que as relações de poder se cristalizassem em estados de dominação. De acordo com Foucault (2008), existem várias tecnologias de dominação que a sociedade desenvolveu para que o indivíduo tenha controle de si mesmo e faça parte de um grupo que usa métodos de repressão pela manutenção do poder e que sanciona esses modos. Dentre elas, as tecnologias do eu, que promovem ações e técnicas sobre o corpo e a alma, articuladas com ideais transcendentes.

\footnotetext{
${ }^{6}$ A reflexão tratada aqui é a que faz o movimento de volta sobre si mesmo, de retorno ao eu. O pensamento é de interrogar a si, prática fomentada pela filosofia. Afasta-se do entendimento de reflexão crítica, qual seja: uma tomada de consciência, no exame de fundamentos e razões de algo, posicionando-se a partir de um conjunto de informações conquistadas com essa análise.
} 
Desse modo, a pesquisa de Mundim e Santos (2012) ganha força, pois proporciona os estudos dos conceitos Ciência e Tecnologia tramados a realidade e ao que se passa com os alunos, mais ao nível da subjetividade. Nesta pesquisa, vincula-se essa prática às tecnologias do eu, porquanto os autores atentam para o que se pensa e sente nas atividades propostas, sendo esse movimento fundamental para a educação, pois coloca os estudantes em contato com suas próprias convicções e pensamentos, operando tecnologias a favor desses princípios que fortalecem um entendimento desse "eu" e da sua construção enquanto ser social.

Os encaminhamentos das discussões acerca dessa temática, pelo autor, partem dos seus estudos sobre a sexualidade na sociedade, suas interdições, regramentos e disciplinamentos ao longo da história ocidental. O sujeito é solicitado a conhecer a si mesmo, por diversos dispositivos subjetivos que são postos a funcionar pelos aparelhos do Estado, principalmente por aqueles que envolvem questões do biopoder, como forças que implicam sobre a vida e que atravessam os indivíduos de forma a garantir o controle e manutenção de uma determinada ordem. Assim, o objeto dos estudos de Foucault acerca das tecnologias do eu é de delinear, historicamente, os diferentes modos pelos quais se desenvolve o conhecimento sobre o "eu", realizando análises que relacionam as Ciências, considerando-as como jogos de verdades, práticas especializadas para compreender a si mesmo.

Essas relações do conhecimento de si e de como as subjetividades são moldadas podem ser percebidas na escola a partir da experimentação realizada por Andrade e Carvalho (2002). Em uma classe do sexto ano, no Ensino de Ciências, é desenvolvido um conjunto de atividades, utilizando-se de procedimentos didáticos que conduzem o pensamento dos alunos, por exemplo, estudos dirigidos realizados na internet e questões formuladas pelos professores. Os resultados de pesquisa indicam um trabalho que oferta aos alunos oportunidades de discussões e reflexões, a partir de procedimentos e recursos didáticos, como textos, músicas e cartazes, os quais promovem, de acordo com os autores, a incorporação, em sala de aula, de diferentes dimensões relacionadas ao Ensino de Ciências. Entretanto, 
essa prática foi direcionada pelos docentes, principalmente na relação crítica do saber, a condução do que o aluno é ou não é, deve ou não ter, o que demonstra o quanto as tecnologias do eu operam modelações de um perfil de estudante considerado ideal pelo sistema e instituições educacionais.

No espaço escolar atual, muitos são os instantes em que os discentes se expressam por meio de uma atitude, como o uso das redes sociais ou a ocupação de espaços virtuais. Entretanto, poucas vezes atenta-se para essas manifestações de ordem subjetiva, que aparecem nos processos de ensino e aprendizagem. É importante buscar, em distintos territórios, modos de constituição com os quais os alunos se identifiquem nessa contemporaneidade, possibilitando diminuir a distância do educando para com o conteúdo, na relação com a escola e o professor. Portanto, atentar para o que se pensa e sente são fundamentais para o cuidado de si, colocando as tecnologias a favor desses princípios.

Procurou-se demonstrar como as tecnologias, neste caso as que implicam o "eu", estão associadas a algum tipo de dominação, para que essas possam operar modos de ser e fazer historicamente construídos como hegemônicos na sociedade, bem como na Educação. Entretanto, Foucault (2008) possibilita pensar nas constituições, formas de aprendizagem e modificação dos indivíduos. Ainda, que certas habilidades edificadas necessitam do investimento de atitudes correspondentes, tenta-se uma força em prol da conversão do olhar para si mesmo. Nesse movimento, arranja-se a concretude de mostrar o que é feito de modo a tangenciar, escapar aos modelos, aos padrões estabelecidos. Diversos meios e técnicas são constituídos para aprisionar e estruturar as pessoas, mas é justamente esse controle que permite que elas saiam desse sistema. É no próprio Estado que se encontram as resistências, como potências criadoras e libertadoras, que ofertam fugas aos disciplinamentos sociais.

Pode-se pensar o Ensino de Ciências, neste contexto, como um processo centrado na pessoa, que valoriza o pensar criativo, inédito, construindo e transformando o modo pelo qual o sujeito faz a experiência de si em relação consigo mesmo. A Educação, conforme Foucault (2012), é 
uma maneira política de manter ou de modificar a apropriação dos discursos. Assim, é nesse território, envolto em práticas de avaliação, controle e disciplinamento, que as tecnologias do eu podem ser mais facilmente mapeadas e suas forças reverberadas, tanto nas potencialidades do sujeito, como também nos modos subjetivos de violência e normalização.

O quanto hoje a subjetividade dos sujeitos é produzida por aquilo que o cerca e atravessa em suas vivências? A partir de uma pesquisa ${ }^{7}$ realizada durante uma semana, quase 700 mil usuários da rede social Facebook tiveram seu feed de notícias manipulado pela própria empresa para avaliar o "contágio emocional" das publicações e como isso afetou o humor dos participantes. Os pesquisadores verificaram se o número de palavras positivas ou negativas nas mensagens lidas pelos indivíduos resultaria em atualizações positivas ou negativas de suas próprias postagens. Concluíram que os sujeitos eram afetados pelo que era compartilhado e mudavam o humor de seus próprios posts depois de uma semana. Com isso, há que se questionar o quanto dessas inferências sobre o que se reflete, sente e seus desdobramentos não é fruto do bombardeamento de informações ou da oferta do que pensar, que é conjurada nos territórios educacionais.

Nessa perspectiva, as subjetividades não ganham destaque tanto quanto a opção por embate de ideologias. A tecnologia do "eu" é reconhecida como algo complexo e que envolve diversos níveis de organização. Assim, segrega-a em campos isolados do saber, por meio da definição de conceitos e áreas que seriam autenticadas como conhecedoras dessa temática. Ainda, certifica determinados grupos que seriam identificados como os detentores desse conhecimento, podendo levar os sujeitos a cuidarem de "si mesmos" por meio de técnicas, disciplinas com conteúdos e metodologias independentes, que os colocariam em contato com o seu interior.

As tecnologias do eu são concebidas como uma afirmação de um viver. O Estado tende a massificar o que, por natureza, é singular na multiplicidade, como a formação humana. O que, de fato, podem os sujeitos

${ }^{7}$ Fonte: http://www.pnas.org/content/111/24/8788.full. Acesso em junho de 2017. 
da Educação nas condições existências que transversalizam o seu cotidiano? A Educação perde, atualmente, referências, sentidos, valores e por vezes, não deixa de lado o modo que se ensina, que desenvolve o conhecimento. Aqui a aposta está nesse movimento de desconstrução como potência para criar e produzir.

Como práticas de Ensino de Ciências contextualizadas à teoria pósestruturalista, recorre-se a temas, onde educador e educando estudam aspectos da realidade que são capazes de impulsionar questões acerca dos modos de constituição enquanto ser social, tais como: uso de agrotóxicos; desmatamento; desemprego causado pelo fechamento de empresas locais; fragilidade no sistema público de atendimento médico; usinas de energia nuclear, hidrelétricas e termoelétricas; uso de aerossóis, destruidores da camada de ozônio; aumento do efeito estufa; utilização dos biocombustíveis; alimentos manipulados geneticamente; marketing e o consumo na sociedade; produtos descartáveis no lugar de bens duráveis; padrões, normas e os modos de controle.

A experiência de si, em que o sujeito, sua história e sua constituição como objeto são consideradas inseparáveis da tecnologia do eu, tornam-se catalisadoras dessas práticas na escola. Sendo assim, a Educação é pensada, não somente como um território em que se aprende e ensina, mas também é vislumbrada produzindo formas de experiências de si nas quais os indivíduos podem se tornar sujeitos de um modo particular. Pensa-se em linhas de fuga ao entendimento acerca da tecnologia, principalmente, pela tecnologia do eu, conforme os estudos de Foucault, permeando conceitos e problematizando a temática em uma perspectiva pós-estruturalista.

\section{Sociedade disciplinar em controle}

De acordo com Foucault (1987), as sociedades se constroem e estabelecem historicamente pelas relações de poder que envolvem a produção de distintas forças, aquelas que negam ou as que permitem determinadas práticas e ações inerentes ao viver social. Estas podem ser provedoras de mecanismos e dispositivos dominantes que englobam os dominados, mas 
também romper, desestruturar os processos de uma determinada ocasião ou movimento, na possibilidade de depor o que é hegemônico e constituído.

Discorrendo sobre a sociedade disciplinar, Foucault (1987) identificou, na segunda metade do século XVIII, o corpo como objeto e alvo de poder, o controle sobre ele e no modo de vida, evitava possíveis levantes e protestos, mostrando-se mais eficiente. Citando como exemplo: o soldado que se tornou algo passível de ser fabricado, uma máquina da qual se tem necessidade ou ainda a gerência sobre o corpo feminino a partir de um modelo estético a ser seguido.

A disciplina é o substrato por onde a sociedade se consolida, adestrando os corpos com o objetivo de multiplicar suas forças, para que possam produzir em suas funções, tanto quanto enfraquecer sua disposição a resistência política. Nesse sentido, o intuito da disciplina assemelha-se menos ao do suplício, enquanto este pode destruir o corpo, a outra, todavia, pretende valer-se ao máximo, esgotá-lo, tal qual uma máquina.

$\mathrm{Na}$ sociedade disciplinar, não se trata da população, mas do corpo. Minuciosamente sobre ele, uma repressão é exercida, que não o deixa escapar, as suas atitudes e sinais são sempre ativos. O domínio se dá na produção que este irá realizar, a sua importância está no seu vigor, na organização de seus atos. O exercício é colocado em primeiro lugar, operando sobre as energias, de forma constante e sucessiva, focando nos processos de funcionamento mais do que nas consequências. Produz códigos que examinam e determinam incessantemente o andamento, os territórios e as oscilações que decorrem dos condicionamentos impostos. De acordo com Foucault (1987), as disciplinas são os métodos que permitem o controle minucioso das operações do corpo, a sujeição de suas forças, impondo uma relação de docilidade e utilidade.

O controle sobre o corpo é feito também nos detalhes que incidem sobre ele, dos aparelhos de Estado, da pedagogia escolar e militar. Alguns dos territórios que o indivíduo ocupa, não escapam nem os pormenores. $\mathrm{O}$ olhar preciso das inspeções, a abrangência dos regulamentos e as técnicas ínfimas que incidem sobre os diferentes ciclos biológicos asseguram a 
disciplina necessária. De acordo com Foucault (1987), a mecânica do poder define como se pode ter o domínio sobre os outros, para que, deste modo, possam operar os métodos seguindo a presteza e o vigor que é determinada. “A disciplina fabrica corpos submissos e exercitados, corpos dóceis. Aumenta as forças do corpo, em termos econômicos de utilidade, e diminui essas mesmas forças, em termos políticos de obediência" (FOUCAULT, 1987, p. 127).

As filas, com suas ações específicas: estático, em pé, sequencialmente; o aluno, em sala de aula, sentado, quieto; são modos de disciplinar os indivíduos, desenvolvendo sua corporeidade. Foucault (1987) afirma que o espaço e o tempo requerem uma disciplina, ou seja, fazem parte do cotidiano dos sujeitos e, por vezes, agenciam punições, vigiando por meio dos territórios que o indivíduo ocupa na sociedade organizada. A escola facilita a manipulação dos estudantes para o seu deslocamento e permanência, em que todos são cuidados, dentro ou fora dessa sistemática. Também, entendem-se as leis como disciplinas legais criadas para regulamentar, organizar e penitenciar; o comportamento, a imagem pela semelhança, inclusive a cultura de gerações, operam para o funcionamento social.

Como exemplo desse poder disciplinar nas escolas, demonstra-se, nas atividades com enfoque no Ensino de Ciências, realizadas por Andrade e Carvalho (2002), o quanto as ações de disciplinamento têm efeitos atualmente. Nas análises efetivadas na turma, foi observado, pelos pesquisadores, que a postura firme do professor somado a um espaço organizado para a prática do projeto resultou em maior atenção e contribuições por parte dos alunos. Essas demonstrações tendem a generalizar que, a partir de uma posição de vigiar e punir, o docente e os gestores terão melhores resultados nos processos educacionais, consolidando esse modelo nas escolas.

A pedagogia tradicional, com sua formação a partir dos mestres, avaliada por uma só prova, onde não havia fases, tratando o discípulo como objeto a ser modelado por processos de transmissão de saberes, é substituída 
pelas disciplinas que compõem uma série a ser vencida para ocorrer uma progressão educacional. Esse é o tempo onde se impõe a prática pedagógica que otimiza os períodos de desenvolvimento, da habilidade adquirida, organizando diferentes estágios, cada um limitado por avaliações. Determina programas que devem ser seguidos, possuindo exercícios com problemas crescentes e, desta forma, classifica, qualifica os sujeitos pelo modo como ultrapassam essas séries. Assim, é assegurada a manutenção do poder, por um controle planejado, com intercessões cirúrgicas que, por meio de correções, erros, falhas e punições, fazem emergir resultados positivos e acertos, um investimento certificado.

Com relação à formação de professores, pode-se citar a proposta de Tenreiro-Vieira e Vieira (2005), que pretende dar conta de um estudo desenvolvido com a finalidade de descrever e analisar as contribuições de um programa de Educação continuada na construção de práticas e metodologias para o Ensino de Ciências. Nos resultados obtidos, concluíram que o programa de formação contribuiu para que os docentes envolvidos promovessem práticas didático-pedagógicas com orientação na temática. Os autores o consideraram como um processo de pesquisa por meio do qual a produção de conhecimentos fosse um investimento na ação educativa, seguindo diretrizes previamente estabelecidas. Essa análise, feita pelos autores, contribui para um pensamento disciplinar, pois sugere que os professores devem estar em constante contato com avaliações de suas práticas, que participem mais de formações oferecidas tanto pelo Estado quanto pelas Universidades e determina que os educadores tenham certos requisitos para atingir um status de formador dos alunos.

O poder, promovido na sociedade disciplinar, tem como objetivo adestrar os indivíduos. É por meio da codificação e de sinais, também na Educação, que a apropriação dos corpos ganha efeito. As forças advindas desse processo são ligadas e multiplicadas para serem aproveitadas como um todo, uma máquina composta por diversos segmentos, mas que operam em um só sentido. A escola é considerada, nessa paisagem, um aparelho de aprender, onde cada aluno, nível e momento estão combinados. Sendo 
utilizados no processo geral de ensino, a eficiência está na ordem que não precisa ser explicada, nem estabelecida, já sendo suficiente para gerar o comportamento desejado (FOUCAULT, 1987).

Nesse modelo disciplinar de sociedade, há mecanismos que são acionados para garantir o controle sobre o que se deseja, que operam na ordem penal, em que privilégios, leis próprias, crimes específicos, medidas repressivas e julgamentos são postos a funcionar para dar sentidos aos objetivos pretendidos. $\mathrm{Na}$ escola, por exemplo, os atrasos, ausências, desatenções e baixos rendimentos são punidos por ações, que poderiam ir de castigo leve a humilhações, bem como determinações por meio de notas ou identidades. São desvios passíveis de sofrerem infrações. Assim, tem-se uma fiscalização que, definida e regulada, está no cerne da prática do ensino, uma máquina que é intrínseca e potencializa sua eficácia.

A sociedade disciplinar avalia os sujeitos e seus conhecimentos com verdade. Assim, legitima ações e pune os que não atingem o nível aceito, qualificando-os para validar os processos. Os comportamentos, principalmente na escola, estando sobre constante vigilância, são valorados como bons ou ruins. Os erros, mesmo aqueles que mediam as aprendizagens, são classificados por notas. "Aprovado" ou "reprovado" são esses os rótulos que permitem avançar, ou não, para um outro ano.

Essas características da sociedade disciplinar são encontradas no estudo desenvolvido por Abreu (2001), que analisa uma aproximação do Ensino de Ciências ao modo tecnológico e profissionalizante do mercado de trabalho como algo positivo. Essa relação se daria no sentido das promoções, tendo como instrumento as avaliações. $\mathrm{O}$ aluno que tivesse um alto aproveitamento estaria apto para operar transformações na sociedade. Caso não atingisse, passaria por recuperações até estar no nível dos demais colegas. De acordo com o autor, o professor também estaria presente nesse sistema, pois seria o educador que além de fazer as avaliações, acompanharia os estudantes nos processos de aprendizagem, recontextualizando o ensino. Assim, podem ser observados modelos de 
sujeitos da Educação sendo fabricados, nesse jogo de recompensas, tentando normalizar o conhecimento por meio de parâmetros avaliativos.

Assim, a sociedade disciplinar se constitui por meio de práticas, que fabricam indivíduos úteis, permitindo a garantia da submissão das forças e dos corpos. Ainda hoje, em muitas escolas brasileiras, pode-se ter acesso a essas produções quando se vislumbram estruturas físicas e espaciais do ambiente, pensadas a partir de um modelo que regula o comportamento dos alunos. $\mathrm{O}$ aspecto da arquitetura mostra-se como forma de punição eficaz através da privação da liberdade, bem como o ir e vir, excluindo o sujeito de um determinado grupo social ou separando alunos em turmas, com espaços separados, classificando cada classe.

$\mathrm{Na}$ prática realizada por Andrade e Carvalho (2002), os procedimentos de pesquisa remetem a exercícios disciplinares, como as discussões em pequenos grupos, com temáticas direcionadas pelo professor, que registra e anota qualquer consideração medida como válida para o objetivo do estudo. Além disso, as escritas extraídas dos estudantes eram condicionadas por perguntas prévias e a avaliação deu-se por meio da observação, medindo o envolvimento na proposta, e provas escritas. Esses mecanismos retiram a potência do corpo, tornam-no apto a uma determinada finalidade, exercita-o para melhorar o desempenho.

Segundo Foucault (1987), o poder é uma prática social e, por isso mesmo, é constituído historicamente e articula-se com a estrutura econômica. A partir dessa concepção, percebe-se como os exercícios de disciplinamento funcionam por meio de dispositivos, bem como quando um corpo se torna adestrado, convertendo-se em útil, submisso ao sistema que se impõe, contribuindo para a estabilização e ordem. As instituições não almejam, primeiramente, punir, mas também se revelam vigilantes, com métodos de correção que não atingem necessariamente o sujeito fisicamente, mas psicologicamente. Outrossim, o controle do tempo assegura a disciplina, evitando atitudes de oposição.

De acordo com os estudos aqui realizados, a sociedade, com seus respectivos regimes, pode ser desmembrada, nos diferentes períodos 
históricos, em soberana, na qual um senhor exerce o poder, por meio de uma vigilância externa, com direito sobre a vida e a morte de seus súditos. Ainda, a disciplinar, na qual as instituições operam dispositivos, que garantem a manutenção de um sistema, principalmente com relação aos corpos dóceis e úteis. Tais práticas, essenciais para o seu funcionamento, ainda estão presentes nos dias atuais. Entretanto, encontra-se, ultimamente, uma crise generalizada dos meios de confinamento e um novo modelo ocupa os espaços deixados, com um controle a distância.

Desse modo, o colapso das instituições modernas, já considerado por Foucault em seus estudos, concebe o surgimento de um novo regime de dominação, denominado por Deleuze (1992), de sociedade de controle. Há mudanças na lógica: uma apresenta diferentes práticas para cada confinamento, enquanto na outra, atual, ocorre uma influência constante, numérica e extensa no corpo social. Desenvolve-se nos limiares da Modernidade e se desenrola para a pós-modernidade, em que mecanismos de poder são imanentes ao social, trazendo consigo a premissa de um caráter totalitário e democrático. O corpo ainda é objeto de disciplinamento, mas, para além disso, o foco recai sobre as populações e grandes massas de pensamento, com redes flexíveis, flutuantes, que colocam a funcionar esses imperativos ${ }^{8}$.

As fábricas, que representam a sociedade disciplinar, com baixos salários para trabalhadores, exigência de alta produção e vigilância constante sobre um corpo único, são substituídas pelas empresas. Com o sistema de prêmio, de acordo com as atitudes dos empregados, dos desafios e concursos impostos, são atribuídas diferentes remunerações. Além disso, há uma motivação extra para que os indivíduos possam estar superando a si mesmos e aos outros a todo instante. Nas empresas, as diferentes classes são substituídas pela cooperação, em que há participação dos empregados nos

\footnotetext{
${ }^{8}$ Foucault (2002) pensa também em um novo tipo de sociedade, que supera a disciplinar, denominada de segurança, em que um dos tipos de dispositivo que garantem a manutenção do poder é o controle. O biopoder opera no corpo social, quando este já está disciplinado. Os Estados vão afirmar, salvar a vida da população, como exemplos: a vacinação e a previdência social.
} 
lucros totais das companhias, as quais, cada vez menos, precisam de pessoas para realizar as demandas.

Na sociedade de controle, há, também, uma rede que classifica, normatiza e sanciona, mas esse status é igualmente temporário. As referências sociais modificam-se constantemente antes mesmo de estabilizar-se. Assim, engendram-se novas subjetividades e percepções em que são oferecidos modos de ser e de pensar que só tendem a contribuir para a manutenção do que está posto. Os desejos, assim como se constroem rapidamente, também são substituídos por outros, que custam mais, despendem, igualmente, trabalho e dedicação maior, sufocando as escolhas em um ciclo degenerativo, em que as aceitações sociais passam pela dedicação que é dada a esse sistema.

Artefatos técnico-científicos são postos a funcionar na sociedade de controle, como é o caso das mídias, com função de distrair, informar, domesticar, massificar e expandir, sem falhas, os imperativos coletivos. Recondiciona também, pela publicidade, diferentes atrativos, dentre eles o consumo e a produção constante de mercadorias, que infringem as liberdades de escolha e condicionam modos de vida e existência. A globalização é alçada como imprescindível, em que as compras e vendas são sempre da ordem do macro, a excelência está na aquisição de um ideal que serve e abrange as necessidades de todos. O Ensino de Ciências percorre esse caminho ao tratar a própria tecnologia como uma mercadoria, na qual, para estar no ápice científico, necessita-se trabalhar com o que há de mais avançado tecnologicamente no comércio.

Nessa sociedade, diversos dispositivos cumprem funções definidas, que englobam o mercado mundial e são usados como estratégias de manutenção de uma hegemonia, bem como de regimes governamentais. $\mathrm{O}$ poder, antes prioritariamente mantido pelo Estado, por meio de seus aparelhos, atualmente, flui pelas grandes corporações, que ditam valores, cobram dívidas e empréstimos a longos prazos. Os indivíduos estão interligados a múltiplas máquinas, tanto em uma pequena escala, como o 
celular, mas também em uma grande, nos satélites, de tal modo que as conexões são ininterruptas e acontecem em um tempo real.

Na Educação, os testes finais, realizados para classificar os alunos, são substituídos, não exclusivamente, pela formação continuada e avaliações sucessivas, isto é, o conhecimento que o aluno "possui" está sendo capturado constantemente pelas provas e trabalhos. Concomitantemente, o professor passa por diferentes julgamentos, mediados pelos resultados obtidos. Demonstra-se, por meio das avaliações, realizadas em todo o Brasil, que vão da alfabetização ao término da Universidade ${ }^{9}$, gerando constantes balizamentos da atuação do professor, tais como as pontuações e médias a serem atingidas e as promoções oferecidas para aqueles que atingirem um nível específico, bem como moldando os saberes investigados em sala de aula por meio da seleção de conteúdos e conhecimentos que farão parte dos testes.

Quem produz o controle nessa sociedade são as próprias tecnologias, como câmaras de vigilância, celulares e as instituições, escolas, agências e a própria população. Cada sujeito que tem internalizado o modo de viver contemporâneo, acaba sendo um vigilante de outro, buscando sempre uma normalidade nas ações, baseado em um ideal instituído. Ainda, como uma submissão do homem à máquina, pode-se pensar os drones, pequenos aviões não tripulados que incorporam os conhecimentos mais avançados, objetivando o domínio do espaço aéreo, do jogo bélico e da comunicação, inclusive sendo usado para fazer entregas de encomendas ${ }^{10}$. Desse modo, tenta-se estabelecer uma relação com a soberania, em que o espaço do

9 O Sistema Nacional de Avaliação da Educação Básica (SAEB), realizado pelo INEP/MEC, abrange estudantes das redes públicas e privadas do país, localizados em área rural e urbana, matriculados na $2^{\mathrm{a}}, 4^{\mathrm{a}}$ e $8^{\mathrm{a}}$ séries (ou $3^{\circ}, 5^{\mathrm{o}}$ e $9^{\circ}$ anos) do Ensino Fundamental e também no $3^{\circ}$ ano do Ensino Médio. São aplicadas provas de Língua Portuguesa e Matemática. O Exame Nacional de Desempenho de Estudantes (ENADE), tem como objetivo aferir o desempenho dos estudantes em relação aos conteúdos programáticos previstos nas diretrizes curriculares do respectivo curso de graduação, e as habilidades e competências em sua formação, sendo aplicado no início e final do curso. Fonte: http://www.educacao.pr.gov.br/modules/conteudo/conteudo.php?conteudo=61. Acesso em maio de 2017.

10 Empresas, com o Google e a Amazon, investem na criação de drones destinados a entregas de pacotes a clientes. Disponível em:

http://www.techtudo.com.br/noticias/noticia/2014/08/google-investe-em-projeto-deentregas-com-drone-assim-como-amazon.html. Acesso em abril de 2017. 
soberano é ocupado pelas máquinas e o de súditos pelos seres humanos, hoje em uma forte dependência desses artefatos.

A adaptação da grande massa populacional ao controle passa pelas corporações e bancos que administram esses processos e tornam-se invisíveis, como o modelo de sociedade de soberania, em que submissa é a população. As mídias sociais passam por uma democratização, onde tudo é passível de publicação e diversos discursos são aceitos para explicar qualquer coisa. Contudo, há produções de sentidos nesse funcionamento, que ditam o que pensar e formas de ação. Por mais que revoltas emerjam nesse contexto, elas prioritariamente usam tecnologias, como as redes sociais, para se articularem, levar o movimento às ruas e serem vistas.

Dentre as questões que contaminam, de diferentes maneiras, o tempo presente, cita-se: a crise ambiental, guerras, pobreza, miséria, desequilíbrios ecológicos, catástrofes, abertura de mercados, inovações tecnológicas e os discursos financeiros. A Educação pode pensar essas implicações com relação aos sujeitos, e como eles se constituem, com o meio em que vive, atravessados por modelos de vida, padrões econômicos e sociais. Os artefatos culturais, a televisão, o rádio, a música são ferramentas potentes que ensinam e legitimam valores, ao difundir verdade e saberes acerca dos modos de se constituir como sujeito na sociedade contemporânea, que se encontram instáveis e provisórios, mas que também são utilizados como escapes dos aprisionamentos inerentes ao funcionamento.

Hoje em dia há exemplos de como o território educacional possui outros desdobramentos: um grupo de pais da Califórnia (EUA), descontentes com a escola "ortodoxa", produz outros sentidos para a sala de aula em casa, com o projeto hackschooling"11. Na ideia de "hackear a escola", para transformar a Educação, apostam em um currículo personalizado com foco na felicidade e em projetos de vida, mais do que em carreiras e notas.

\footnotetext{
11 Mais informações acerca do projeto: desafiosdaeducacao.com.br/como-os-hackers-daeducacao-querem-transformar-ensino/ Acesso em março de 2017.
} 
No Brasil, eventos ${ }^{12}$ têm reunido hackers, ligados a instituições de ensino, para pensar e produzir ações educacionais. As propostas incluem o desenvolvimento de aplicativos, o estudo de relações entre os dados do Instituto Nacional de Estudos e Pesquisas Educacionais Anísio Teixeira (INEP), outras bases e ferramentas. Além disso, projetos como a "Escola que Queremos"13, site capaz de gerar um indicador de qualidade inteligente de uma determinada escola que pode ser comparado com as médias municipal, estadual e do país, possuem investimentos que põem a funcionar outros desdobramentos na geração de ideias e conhecimentos nesse território.

Esses temas, bem como os elementos citados acima, possuem um caráter exploratório e contextualizador, pois o desenvolvimento deles em sala de aula gera desdobramentos na realidade dos alunos e professores, impulsionando a curiosidade e tramando a teoria na prática. Ainda, por terem um caráter interdisciplinar, são capazes de relacionar-se com outras áreas do conhecimento e atingir mais concretude nos processos de ensino e aprendizagem na medida em que são contemporâneos e estão presentes no cotidiano dos alunos.

\section{Considerações finais}

Enfim, a aposta é em um pensamento científico que desenvolva a produção de novos sentidos, numa prática educacional que deixa de lado as convenções, o já dito, normalizado, que impactam a sociedade. Difundir as possíveis consequências de pensar o Ensino de Ciências em uma outra lógica, que não a concebida no modo tradicional; desenvolver essa outra via, afastando-se das verdades absolutas, totalitárias e neutras, implica esvaziar os modelos de referências e possibilitar uma abertura no pensamento, evitando a exclusão de determinados saberes.

\footnotetext{
12 Fonte: revistaescola.abril.com.br/blogs/tecnologia-educacao/2013/04/12/uma-maratonade-hackers-pela-educacao/ Acesso em abril de 2017.

${ }^{13}$ Fonte: hubbrasilia.wordpress.com/2013/05/17/hackers-pela-educacao/ Acesso em março de 2017.
} 
Respostas definitivas não são cabíveis nesta perspectiva, mas sim possibilidades de problematizar o campo da Educação e do Ensino de Ciências, por meio dos conceitos de Ciência, Tecnologia e Sociedade aqui analisados, sem dúvida, de forma superficial quando comparada com o aprofundamento que cada um representa nos estudos educacionais. Entretanto, os questionamentos inerentes à pesquisa permeiam as discussões, considerados potentes para pensar de outros modos as temáticas estudadas e contribuindo para a área ao promover outras possibilidades de pensar esses conceitos.

As considerações realizadas dentro da concepção tradicional da Educação solicitam uma outra visão da Ciência, mas que ainda retomam métodos e epistemologias fomentadas pelos caminhos régios e maiores, é como repetir o mesmo. Há que se perfurar esses territórios, promovendo uma agitação aos modelos, buscando, trabalhar a temática a partir das problematizações e das singularidades nas produções coletivas articuladas à Ciência menor, as tecnologias do eu imersos nessa sociedade de controle.

De fato, a tecnologia, vista como um artefato, trouxe para a Educação diversos benefícios, inclusive na relação de si, com outros, no ensino e conhecimento. Entretanto, não se aprofundam questões que problematizam as subjetividades dos sujeitos. Atualmente, há muitas imagens disponíveis que povoam o pensamento, com aparências e consumos instantâneos, bem como promessas de receitas para se atingir o saber. A partir desse cuidado de si, intensificam-se as mudanças nessas relações. Conforme os estudos de Foucault, é preciso conhecer a si mesmo e não renunciar ao que é próprio de cada um, para não se perder diante dessas ofertas que inundam a Educação com promessas e discursos salvacionistas.

Atualmente, a sociedade coloca-se distante dessa perspectiva do cuidado de si. A Ciência afasta-se das considerações de descoberta da sua verdade, não como um produto dos estudos, mas de uma prática acompanhada de reflexão constante sobre as próprias ações, atitudes e de como pode-se modificá-las. Diante do exposto, pensa-se uma defesa para o Ensino de Ciências, que crie estratégias de existências, que reivindique a 
trama de teorias e práticas, em meio a um conjunto de possibilidades mutantes, como a que está disposta no panorama atual, operando os conteúdos científicos na e com a sociedade. Sendo possível ter formas outras de ser e viver na contemporaneidade, produzindo coletivamente, sem deixar a capacidade de cada sujeito menosprezada. É importante que a homogeneidade padeça diante da singularidade, capaz de minimizar as mazelas vividas neste cenário.

Enunciados, carregados de poder e saber, que produzem verdades, atravessam e constituem os sujeitos deste tempo, inseridos nessa sociedade. Há interpelação de discursos científicos, dentre outros, ditos como verdadeiros, que são capturados diariamente com chamadas persuasivas e sedutoras. Compõe-se um tempo de constante desenvolvimento técnico e científico. Em uma sociedade de degradação do meio ambiente e do consumo exacerbado, em que tudo se transforma rapidamente, há hoje um estado de incompletude e de constantes necessidades.

O Ensino de Ciências concorre para que a sociedade de controle, bem como a Educação tenham impregnadas linhas de forças em suas estruturas e verdades que sustentam modos de ser padronizados. O desenvolvimento industrial, cultural e dos meios digitais se tornam propagadores desses costumes, o que leva a uma sensação e um sentimento de que todos estão vivendo em um mesmo contexto.

Por isso, interessa criar outros espaços e tempos na Educação a fim de mudar essa metodologia aplicada, que revela necessidade de transformações, para que o aluno compreenda a sua importância no seu grupo e que sua diferença pode produzir e transformar. Percebe-se a importância de não permanecer de propostas que reivindicam o mesmo, totalizante e unitário, reinventando distintas maneiras de se relacionar enquanto seres sociais, em um tempo em que se necessita de revoluções políticas e culturais, para que a vida esteja menos perturbada. A Educação, nessa perspectiva, contribui para um pensamento que vai além do senso crítico já reivindicado nesse território, mas que insere a multiplicidade, o 
singular, como pressupostos que procuram mobilizar o pensamento diante das resistências em que se é experimentado.

\section{Referências}

ABREU, R. G. de. Tecnologia e ensino de Ciências: recontextualização no novo Ensino Médio. In: Encontro nacional de pesquisa e educaşão em ciências, Atibaia, SP: Abrapec, 2001.

ANDRADE, E. C. P. de; CARVALHO, L. M. de. O proálcool e algumas relações CTS concebidas por alunos de $6^{\mathrm{a}}$ série do Ensino Fundamental. Ciência \& Educaşão, v. 8, n. 2, p. 167-185, 2002.

ANGOTTI, J. A. P.; AUTH, M. A. Ciência e tecnologia: implicações sociais e o papel da educação. Ciência \& Educação, v. 7, n. 1, p. 15-27, 2001.

AULER, D.; DELIZOICOV, D. Educação CTS: articulação entre pressupostos do educador Paulo Freire e referenciais ligados ao movimento CTS. In: Seminário Ibérico CTS no Ensino das Ciências - Las Relaciones CTS en la Educación Científica, v. 4, 2006.

CHASSOT, A. Sete escritos sobre educação e ciência. São Paulo: Cortez, 2008.

DELEUZE, Gilles. Post-scriptum sobre as sociedades de controle. In: Conversaçoes. Rio de Janeiro: Editora 34, p. 223-230, 1992.

DELEUZE, Gilles; GUATTARI, Felix. Mil Platôs: capitalismo e esquizofrenia. v.5. 2.ed. São Paulo: Editora 34, 2012.

FAGUNDES, S. M. K. Produções em educação em ciências sob a perspectiva CTS. Encontro Nacional de Pesquisadores em Educação em Ciências, Santa Catarina, 2009 .

FOUCAULT, Michel. Vigiar e punir: nascimento das prisões. Petrópolis, RJ: Vozes, 1987. . A ordem do discurso. 22.ed. São Paulo: Edições Loyola, 2012. Tecnologías del yo. Buenos Aires: Paidó, 2008.

MUNDIM, J. V.; SANTOS, W. L. P. dos. Ensino de Ciências no ensino fundamental por meio de temas sociocientíficos: análise de uma prática pedagógica com vista à superação do ensino disciplinar. Ciência \& Educação, v. 18, n. 4, p. 787-802, 2012. 
TENREIRO-VIEIRA, C.; VIEIRA, R. M. Construção de práticas didáticopedagógicas com orientação CTS: impacto de um programa de formação continuada de professores de ciências do ensino básico. Ciência \& Educação, v. 11, n. 2, p. 191-211, 2005. 